\title{
Tráfico ilícito de arqueología en Argentina: ¿mercado, corrupción, política, dependencia económica o incapacidad? ${ }^{1}$
}

\section{Illicit traffic of archaeological objects in Argentina: market, corruption, policy, economic dependence or incapacity?}

El presente artículo expone un estado de la cuestión sobre la situación del tráfico ilícito de bienes arqueológicos en América Latina, en general, y de manera particular en Argentina, prestando especial atención a sus causas y consecuencias. Se analiza la situación y se describen las acciones legales y gubernamentales adoptadas. Finalmente se proponen soluciones para combatir el grave estado del patrimonio arqueológico en Argentina.

Palabras clave: tráfico ilícito, antigüedades, corrupción, Argentina, colecciones, legislación, falsificaciones.
This study exposes the current state of illicit traffic of archaeological goods in Latin America, in particular in Argentina. It analyses the situation and describes the adoption of legal and governmental actions. It proposes certain solutions to fight the grave state of Argentinian archaeological heritage.

Keywords: illicit traffic, antiquities, corruption, Argentina, collections, legislation, forgeries. 
Hace varios años el experto en el tráfico ilícito internacional de obras de arte Neil Brodie pidió un artículo sobre el tema con lo que sucedía en Argentina. Lo titulé: “¿Qué sucede a la vuelta de la esquina?”, al observar que buena parte de América Latina y en este caso de Argentina, tenían características diferentes a lo que indicaba la bibliografía internacional sobre el tema, habituada a Egipto, Iraq o México. Había que comenzar a mirar desde adentro y no desde afuera y la falta de bibliografía era casi absoluta. Parecía que los problemas de la realidad no se veían, que el asunto se reducía a otro comercio ilícito más, al que había que combatir, y de leyes que había que hacer y tratar de aplicar; es decir: darles trabajo a los abogados y a los policías. Parecía una concepción heredada de los años de las dictaduras militares más que un problema que afecta gravemente a un campo científico manejado por académicos. Al menos en sus manos estaba su comprensión, la gestión y el establecimiento de políticas, lo demás era necesario, pero no era el eje del problema. Sabemos que la represión no resuelve nada.

Lo que veíamos al inicio de este siglo era un tema grave que afectaba el patrimonio y de allí la necesidad de mostrar que los grandes robos fueron hechos por la más alta jerarquía de la Iglesia católica, por políticos y sus allegados o por grupos paramilitares auspiciados por el gobierno dictatorial antes y después. Y para esos casos el problema no era la falta de legislación sino la de cualquier mecanismo eficiente. Ya se vislumbraba el futuro que tendría el país: además de ser un exportador de antigüedades (como otros de América Latina), se definía el nuevo papel de intermediario. Sin abandonar el saqueo de lo propio este sería el lugar del "blanqueo" de colecciones provenientes de otros países los que sí tenían legislación proteccionista. Es decir, era usar Argentina (y dejarse usar) para reexportar objetos de terceros, lo que puede hacerse sin problemas, o al menos nada grave. Parte del arte antiguo africano que llega a Estados Unidos hace escalas en Panamá y Argentina, ni hablar de lo que proviene de Perú, Bolivia, Venezuela y Colombia, ahora incluso México y Guatemala o lo atribuido a ellos que llega de Honduras, Belice y El Salvador.

El tema no era nuevo: durante la Segunda Guerra Mundial se usaron los museos de Buenos Aires para exhibir obras robadas en Europa y de esa manera crearles una genealogía que posibilitara su venta. Cientos de cuadros y obras de arte pasaron por las paredes y vitrinas de los principales museos, se publicaron en hermosos catálogos pagados por los que exponían y luego se vendieron legalmente al exterior. Y hubo que esperar medio siglo para saberlo, a que Estados Unidos desclasificase su información militar secreta sobre esos años. La mayor parte de los argentinos involucrados no eran ni nazis ni traficantes: casi todos eran coleccionistas, parte de lo más selecto de la aristocracia local, coludidos con funcionarios del gobierno y conocidos museólogos. Y así grandes colecciones como la Thyssen y la Cambó, entraron, permanecieron y salieron con el beneplácito de las autoridades, o al menos con el mirar hacia otro lado. El caso de Cambó, como contrabando avalado por la
Embajada de España, fue un escándalo internacional en 1952. Pero todo eso ya ha sido publicado.

Para la arqueología las cosas eran algo diferentes: el eje del problema que siempre se discutía entre especialistas eran las colecciones privadas que se habían formado desde el siglo XIx. Como si en aquella época hubiera habido alguna otra opción y que de allí no hubieran surgido los museos que aún tenemos. Pero la venta al exterior para la segunda mitad del siglo xx era poca, casi inexistente para la escala internacional. Los objetos precolombinos argentinos lentamente perdieron valor en el mercado por su falta de difusión, y salvo que se vendiera una rarísima máscara de piedra o una escultura de las llamadas suplicantes, no había objetos en los remates, ni siquiera en los de segunda categoría. Una urna funeraria de la región noroeste - las estéticamente de mayor precio- podía valer (y aún vale) U\$ 200/300 en el anticuario. Las piezas que lograron valores más importantes alcanzan los U\$ 5000 y son excepcionales; valores nimios en el mundo del tráfico. Es decir: hace poco más de medio siglo solo había un reducido mercado interno porque las grandes colecciones se habían cerrado y pasado a formar parte de museos locales, o se habían disgregado. Ya no era socialmente validante el coleccionar ese tipo de objetos. Es decir, parar el tráfico era posible si alguien lo hubiera analizado seriamente.

Pero la década de 1970 trajo la moda de lo nacional y popular con un rebrote interno en que la nueva burguesía quería tener objetos prehispánicos e históricos, y se abrieron negocios a la calle que vendían arqueología. Eran piezas de bajo valor para el consumo de esa clase en ascenso que expresaba la política populista: música en español, muebles rústicos, recuperar lo popular del pasado y revivir los nacionalismos de ultraderecha del inicio del siglo $\mathrm{xx}$ con una máscara de izquierdas. Se destruían sitios arqueológicos para satisfacer imágenes burguesas de pertenencia política, que a su vez apoyaban el nacionalismo supuestamente popular. Para ese momento el tema de lo que salía del país se hizo más simple: la culpa la tenía el imperialismo y la dependencia económica; así, sin más, simple y claro. La responsabilidad la tenían otros. La idea de un imperialismo voraz interesado en cooptar nuestro patrimonio quedó en el imaginario de los propios arqueólogos y llega al presente sin que haya un solo estudio sobre el tema.

El conflicto comenzó en el año 2003 cuando el Instituto Nacional de Antropología logró que se sancionara una ley nacional centrada en las autorizaciones a los arqueólogos para hacer su trabajo, y en el registro de las colecciones privadas, a la vez establecía que la propiedad -no la tenencia o su trasmisión que eran legales- era del Estado nacional. Magnífico gesto, es decir, la existencia de una legislación de ese tipo, pero la realidad es que la ley fue manejada para darle el poder de control de un campo del conocimiento a un grupo de especialistas, y realmente solo se usó para actuar contra algunos coleccionistas que pertenecían - por extracción política y pertenencia social- a grupos políticos opositores. Y también para controlar qué hacía quién y dónde 
y dar o no permisos para excavar, generando una nueva burocracia con poder sobre el quehacer arqueológico.

La ley "ennegreció” el pequeño mercado local, el que sin desaparecer quedó escondido, si bien lo redujo y eso fue positivo, incluso con actos públicos de requisa, no dejó de existir, cambió la forma de hacerse. Y actuó negativamente sobre el tráfico ya que al hacer más difícil acceder a las piezas las hizo aumentar su valor y ser más apetecibles. Los precios internacionales subieron y aumentó el mercado externo; sucede aquí y en todo el mundo, simple problema de oferta y demanda. Un resultado esperado, pero nunca tomado en consideración. La ley —buena en su intencionalidad - llegaba de manos interesadas para provecho de algunos en acumular poder, no importando sus efectos. Nunca se publicó un estudio sobre el mercado o el tráfico de arqueología en el país, solo compilaciones legales como si se aplicaran realmente más allá de su mera existencia.

Lo primero que se criticó fue que la ley no incluía las palabras conservar, preservar o restaurar, ni para los bienes ni para los sitios; solo se dedicaba a la tenencia de los objetos y no hablaba de saqueo más que como un tema de otros y no como una realidad conocida, incluso las fichas de registro de los objetos no tomaban en cuenta esos temas lo que en los casos judiciales se puso en evidencia. Se demoró quince años para arreglar todo eso y siquiera hacerlas digitales, ya que se habían pensado en la burocracia del papel y la copia. La ley dedica más de la mitad de sus artículos a los requisitos que deben cumplir los profesionales, y no se cita a los saqueadores y menos a los exportadores o a los comerciantes.

Esa capacidad que otorga la ley para decidir sobre los proyectos de investigación, sin ocuparse del problema del tráfico al grado de confundirlo con el coleccionismo, redujo el trabajo de campo, pero no paró el mercado. El eje de la aplicación de la legislación pasó por los permisos a los profesionales, produciendo problemas absurdos como otorgar con exclusividad la mitad del territorio de una provincia (estado), o que no se los renueve en diez años. $\mathrm{Ni}$ hablar de la arqueología de rescate, la que debe esperar a veces un año para ser autorizada perdiendo toda capacidad y eficiencia. Por lo general es una burocracia lenta, pesada y de decisiones personales. La buena voluntad de la ley nacional terminó en la acumulación de poder de unos pocos y la menor presencia de arqueólogos en el campo, sin afectar el tráfico ilegal, solo lo hizo más complejo. Y debemos tener en cuenta que las eternas crisis económicas producen que más del $50 \%$ de los arqueólogos del país no se dediquen con exclusividad al tema, por la falta de recursos y de oportunidades.

Tema grave fue legislar sin evaluar los posibles efectos negativos de una ley que solo dio tres meses (90 días) para regularizar todas las colecciones nacionales, públicas y privadas. Y si bien algunos pudieron cumplirlo, el resto no se enteró, o no había ante quien hacerlo en su región, o no llegaba información fehaciente. Resultado: trabajo para los abogados y muy poco para la arqueología. Y se produjo la inevitable "diáspora de la arqueología": las mayores colecciones se esfumaron, salieron del país, se cubrieron con fundaciones $\mathrm{u}$ otros artificios, o se sumergieron en el submundo de lo ilegal que todos conocen y del que nadie dice nada. Uno de esos efectos, previsible si se lo hubiera estudiado, es que la migración al exterior hizo que nuevamente aparecieran en las grandes casas de remates objetos argentinos de primera línea. Habían pasado a ser apetecibles para el comprador internacional aumentando el valor e incentivando el tráfico. Una máscara de piedra llegó a ofrecerse (no se vendió) en U\$ 50 mil, cuando poco antes valía el $10 \%$. Eso significaba que el saqueo volvía a crecer. Obviamente que era bueno legislar y tratar de aplicar las leyes, pero primero hay que conocer sus posibles efectos para mitigarlos a tiempo. El aceptar donaciones para crear un nuevo gran museo nacional fue el intento de una salida posible que fue rechazada, hay otras que habría que estudiarlas, aunque ya es tarde y eso a nadie se le ocurre. Al prohibir algo y no dar una salida, se genera un problema mayor.

El resultado final fue la proliferación de libros y artículos sobre la legislación nacional, estatal y municipal (surgieron decenas de leyes locales que jamás se han aplicado, aunque es bueno que las haya), análisis legales, discusiones, eventos y congresos para hablar de leyes y los abogados pasaron a la fama. El tema se transformó en un campo teórico de discusión en que nadie cuestionó la falta de aplicación a la realidad; Interpol había comenzado a actuar en el tema, pero con un único especialista. La realidad era que había surgido una nueva burocracia en el estado. Y se había establecido quién daba permiso a quién para trabajar, es decir, se había consolidado el poder dentro del campo profesional; ya no eran los museos o instituciones sino las burocracias públicas. Los traficantes y el saqueo ni se enteraron de todo eso, pasaron a ganar más dinero, aunque tomando nuevas precauciones y trabajando en silencio.

Para los primeros años de este siglo comenzaron a vislumbrarse facetas que mostraban que el tema era más complejo que lo que había sido. Un par de sonados casos judiciales pusieron en evidencia la existencia de diversos estamentos de una trama social dedicada a lo ilegal. No era simplemente Saqueadores vs. Arqueólogos. La estructura se iniciaba en el campesino que excava tumbas (el llamado huaquero en estas tierras sudamericanas), un modesto trabajador del campo pauperizado sin otra posibilidad que eso o dedicarse a trabajar para el narcotráfico. Luego los objetos pasaban al comprador circulante quien es un poblador local con recursos, o el político de la localidad (otras veces es la policía, la gendarmería u otra fuerza militar), de él llegan las piezas al comprador de Buenos Aires, Salta, Córdoba o Rosario, quien junta objetos en cantidad y los traslada a la gran ciudad. Es el encargado de distribuir entre los vendedores con o sin comercios (conocidos, aunque silenciados; solo hubo acciones en un caso desde aquella fecha), y de ellos pasa a los coleccionistas grandes o chicos. Los responsables de la exportación, un grupo muy reducido, reciben la mercadería del vendedor, quien ya sabe lo que le interesa a cada uno. Y sacarlo del país era y es simple, ya que los controles son lábiles, o son corruptos, o no pueden ejecutar sus controles por múltiples razones: son incapaces de cumplirlos 
ya que no entienden del tema, o están ocupados en otros delitos fronterizos como el manejar el contrabando o robar en los aeropuertos, cosa que nuestros periódicos publican a diario: las mafias de las aduanas, de los puertos y aeropuertos. Pensemos que el país creó una "ruta fluvial" que corre por el río Paraná a lo largo de 2500 kilómetros y la aduana la hace la misma empresa que tiene la concesión.

Y si no, está el camino más simple y barato, el que se ha puesto en evidencia con los sonados casos de corrupción de los últimos años: cruzar al país vecino, Uruguay, que no tiene leyes de control arqueológico, a donde se llega con automóvil o con una simple lancha a motor cruzando el río. Valga que los aviones privados, aunque lleguen del exterior, no son revisados (ni hablar de los aeropuertos privados), lo que terminó con casos como los de los políticos pasando maletas de dinero. Es cierto que se hizo un intento de darle información a la policía de aeronáutica, de poner carteles en los aeropuertos, y hubo algunas capturas por delación; pero no hubo ni hay una política, eso solo sirve para que un funcionario salga en los periódicos.

Resulta interesante saber que los dos casos más sonados de juicios hechos contra coleccionistas, incluso uno por el supuesto robo de otra colección privada, los perdió el estado nacional: habían sido maniobras en las que no importaba perder o ganar, sino establecer en los medios de comunicación quién era el malo y quién el bueno, para descolocar a alguien en sus aspiraciones políticas y ubicar a otros. Un caso fue el límite: cuando al perito internacional que debía opinar sobre la autenticidad de las piezas porque alegaba la defensa que eran reproducciones, se le pidió que lo hiciera "a cajón cerrado", con lo que renunció. Al abrirse los cajones más tarde, guardados en la institución responsable de la arqueología, los objetos efectivamente habían sido reemplazados por cosas sin valor: juicio perdido. Pero ya había el compromiso de regresarle a Perú los objetos, por lo que la mitad del envío fue artesanía. Y no es que no hubiera algunas requisas positivas y acciones de importancia, el problema es la incapacidad de establecer políticas continuas y consecuentes.

Mientras tanto la arqueología está viviendo un enorme cambio en el mundo: se ha acabado la "arqueología de los objetos". Ya no importa la belleza de una vasija sino averiguar su contenido, su uso, sus relaciones con la sociedad, su significado, su composición material, su derrotero hasta llegar al sitio en que se rompió, su producción. Absurdo, pero la ley nacional se centraba en registrar objetos enteros sin establecer normativas para los sitios, ni siquiera para ubicarlos adecuadamente, ni hablemos de que pasen al estado o que se los preserve y restaure. Eso, en lugar de aflojar la tensa relación con los coleccionistas (que eran realmente pocos) ya que para cerrar el problema propusieron en 2006 hacer una descomunal donación para fundar un Museo Nacional de Arte Precolombino - que el presidente de la nación avaló-, pero el conjunto más conservador de la arqueología profesional se opuso: la arqueología no era arte y no se podía exhibir lo que había sido saqueado. Tan fuerte fue la polémica y tantas acusaciones se lanzaron al aire, que sí se abrió una Sala de Arte Precolombino en el Museo Nacional de Bellas Artes la que a meses tuvo que cerrar, porque el gobierno populista consideró que era denigrante para los pueblos originarios. Y hubo que esperar diez años a que un nuevo gobierno abriera otra sala, recibiendo tres grandes colecciones preexistentes, y que ahora, ante cambios de gobierno se pone en duda su continuidad. Es decir: es indigno mostrarlas (en buena medida es cierto), pero no lo es el guardarlas en una bodega. Tema para reflexionar. Se protegen los objetos para que no salgan del país a la vez que se impide que la sociedad los conozca o contemple. Se impide que haya una lectura estética desde el presente a los objetos del pasado, lo que en última instancia es antidemocrático. Si un objeto fue hecho con funciones ceremoniales o funerarias, eso no implica que no lo veamos también desde nuestra propia mirada. Es algo que el mundo ha superado hace mucho. Vamos a cualquier museo y vemos imágenes religiosas, desde católicas hasta budistas, y las apreciamos por su simbolismo, pero también estéticamente. Pensemos en la tumba de Tutankhamón.

Volviendo al saqueo, si comenzamos por el campesino que va a la montaña o a la selva a buscar tumbas, hay muchos aspectos y no están estudiados. En Colombia primero, luego en Perú y ya en otros países, ha habido antropólogos y etnólogos que han viajado con los saqueadores y observado lo que sucede. Desde el verdadero ladrón sin reparo moral alguno hasta el que no tiene otra opción. La crisis económica endémica, con más del $60 \%$ de la población en la pobreza - la mayoría viviendo en las zonas más ricas en arqueología-, solo tienen dos opciones: o la droga o el saqueo. Y abrir tumbas es más seguro; en último caso tendrá que pagarle a la policía.

Debemos, a la vez que discutimos, mirar desde una perspectiva de respeto a los pueblos originarios, tema que ha generado conflictos dentro de la antropología y que todos conocemos. En este tema el choque se produce cuando el alegato del saqueador es: "nuestros antepasados dejaron enterrada su herencia para que nosotros la saquemos cuando la necesitemos". En ese caso el derecho tradicional no puede responder nada. Si el respeto a los pueblos originarios implica también sus creencias y sus herencias, las que llegan por caminos diferentes a las nuestras, hay ahí una interesante polémica con las comunidades. México, Guatemala, Honduras, Perú, Bolivia, han avanzado en el tema y los museos comunitarios son expresión de eso. Parar el saqueo y la exportación no es solo educación y ley, implica encontrar caminos económicos dignos para una enorme masa de población, es luchar contra el narcotráfico, es educar en serio, es discutir y avanzar en el derecho comunitario; no pasa por reprimir o hacer más leyes que no se aplican. Porque el respeto a las comunidades originarias lleva a decidir el impedir que el arqueólogo occidental excave, lo que en México y Perú ha sucedido cien veces y con violencia. Y hablando de México, o Bolivia, o Colombia, por suerte aún estamos lejos de que los que saquean y exportan sean los narcotraficantes, dueños por la fuerza de enormes 
territorios donde ellos explotan al campesino hasta límites mortales.

En 1910 uno de los fundadores de la arqueología científica del país, Juan Bautista Ambrosetti, publicó un libro sobre los objetos prehispánicos hechos de metal. E incluyó un capítulo sobre las falsificaciones que solo podían detectarse con análisis de la composición del material; y eran muchas. Resultaba incomprensible porque se suponía que en ese momento no había aún presencia argentina en el mercado internacional, y en el nacional no pasaba de haber media docena de coleccionistas y muy pocos arqueólogos. Pues ahí estaba el error y algunos historiadores de las falsificaciones (de otros países) lo han entendido y logrado alcances notables para identificar piezas, incluso en los grandes museos (recomendamos leer los libros de Adam Sellen al respecto). Sí habían falsificaciones y mercado desde mitad del siglo XIX, lo que pasaba era que no lo sabíamos o no quería- mos saberlo, nadie se había interesado en estudiar el mercado de las antigüedades de todas o cualquier forma, así como aún hoy no hay estudios sobre el mercado de objetos arqueológicos o la forma en que opera el tráfico. Más de un siglo desde Ambrosetti y no se logró avanzar. Un ejemplo es que el fundador del museo más importante del país, el de La Plata, trajo objetos falsos desde México a finales del siglo XIX y siguen en exhibición. Absurdamente algunas de esas piezas ya las habían publicado esos países como supercherías, en libros que están en la biblioteca de los museos que los exhiben. ¿Es posible que nadie haya leído sobre el tema?

Parecería que el tema de lo falso no se cruza con el del tráfico, o al menos se ha relegado el tema: no solo no hay publicación seria alguna sobre el tema (interesante estudiar ese faltante), sino que nadie se imaginó que una proporción alarmante de los objetos en el mercado son falsos. Y por lo tanto

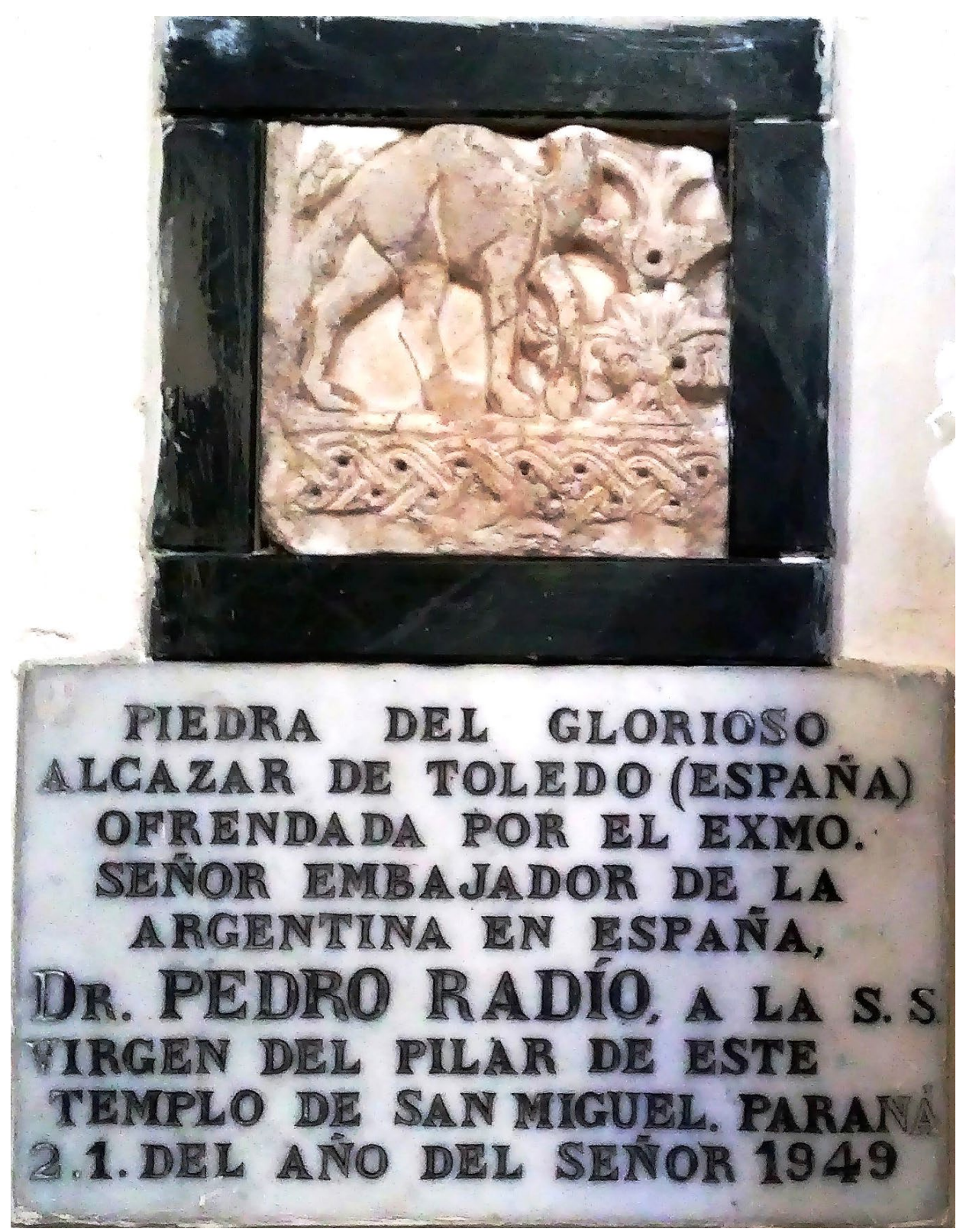

Figura 1. Piedra del Alcázar de Toledo. 
gran parte de lo que sale al exterior. Al publicarse como auténticos por sus propietarios, al exhibirse en los museos por desconocimiento, y ante la falta de estudios, se van consolidando en el mercado como mercancías auténticas y de calidad. Valga de ejemplo de los objetos más cotizados, las máscaras de piedra: poco comunes, se conocen desde hace un siglo y se asociaron a rituales funerarios. Jamás se encontró una en su contexto original. Hoy hay algunas que son simples copias de las publicadas y exhibidas, pero no hay ninguna garantía de que aquellas no sean también falsas. ¿Cómo encaramos el estudio del tráfico si estamos hablando de que al menos el $50 \%$ de lo que existe en colecciones privadas y en el mercado es falso? Pero como provienen de grandes personalidades de hace un siglo siguen siendo elementos considerados como indiscutibles. No parece ser un tema menor para tomar en cuenta; quizás la difusión de esto podría bajar los precios y reducir apetencias; el arqueólogo hoy solo trabaja con lo que él mismo excava y si necesita objetos de referencia los toma con la precaución adecuada. Este tipo de acciones no le hace mal a la arqueología sino al mercado porque confunde al comprador que desvía los fondos hacia otras cosas.

En los inicios de este siglo comenzó en el país una actividad ilícita inversa: el traer objetos desde los países limítrofes. Nada de buena calidad o gran precio y mucha falsificación; justamente lo más barato y simple es lo auténtico, lo que se falsifica es lo que vale la pena vender. Es lo que se llama contrabando hormiga que se hace desde Bolivia y Perú, destinado a las colecciones que compran a pequeña escala. También pasan a través de Paraguay, una frontera totalmente permeable. Juegan con la omnipotencia del comprador que no va a acudir a un experto por algo de pocos dólares, que cree que sabe sin realmente entender. Valga un ejemplo: una piedra inca, un pequeño ídolo o una cerámica estilo Cuzco Imperial, pudo llegar en la expansión incaica o en el día de ayer, nadie puede decir que fue traficada al no ser local.

Tenemos el caso de los rehues (maderas talladas de gran tamaño) de los mapuches chilenos, que los hubo en Argentina y estuvieron en uso hasta el siglo xx. Extrañamente desde hace menos de diez años el principal vendedor está a más de mil kilómetros de donde existieron, y algunos están tallados en durmientes del ferrocarril. Es una fábrica de falsificaciones obvias que entran en las colecciones, se publican, se exhiben y algún día saldrán del país como auténticas. La madera es antigua, de árboles caídos, la talla es lo moderno. Y lo que las hormigas no logran vender se reúne hasta llenar un contenedor, el que sale al exterior a cifras irrisorias.

Solo recorriendo, oyendo, hablando, caminando y visitando a coleccionistas, saqueadores, exportadores y comerciantes, viendo su manera de actuar y conociendo sus artimañas, analizando sus costos $\mathrm{y}$ beneficios, se podrá establecer una política seria. Y viendo la otra cara: la de la corrupción que facilita todo esto. Por eso no basta con generar leyes o tratar de ajustar su aplicación, aunque eso es bueno, lo que falta es instrumentar instituciones y expertos que conozcan los derroteros del tráfico desde el inicio hasta el comprador final por más lejos que esté. Que se mire el problema desde adentro y no desde afuera.

\author{
Daniel Schávelzon \\ Centro de Arqueología Urbana \\ Ciudad Universitaria \\ Buenos Aires (1428), Argentina \\ dschavelzon@fibertel.com.ar
}

Data de recepció: 10/10/2019 Data d'acceptació: 28/11/2019 